\title{
A REVIEW OF APPROACHES FOR AUTOMATED HABITAT MAPPING AND THEIR POTENTIAL ADDED VALUE FOR BIODIVERSITY MONITORING PROJECTS
}

\author{
Rob H.G. JONGMAN ${ }^{1}$, CASPAR A. MÜCHER ${ }^{1}$, Robert G.H.BUnCE ${ }^{2}$, MAIT LANG ${ }^{2}$ \\ AND KALEV SEPP ${ }^{2}$ \\ ${ }^{1}$ Wageningen Environmental Research, Wageningen University and Research, PO Box 47, \\ Wageningen 6700, the Netherlands \\ ${ }^{2}$ Estonian University of Life Sciences, Kreutzwaldi 5, 51014 Tartu, Estonia \\ *Corresponding author e-mail: rob.jongman@xs4all.nl
}

Received: $9^{\text {th }}$ July 2019, Accepted: $5^{\text {th }}$ September 2019

\begin{abstract}
Habitats are important indicators of biodiversity in their own right, as well as being linked to species, hence their widespread use in reporting on nature conservation planning and policy. For reporting consistent mapping and monitoring habitat extent and change is important. Remote Sensing techniques are becoming an important tool for this. In this paper we describe four examples of methods of semi-automated mapping using Remote Sensing. Because the most effective way of improving the accuracy of the estimation of habitat area is by increasing the sample number, it is important to develop methods for reducing in situ surveys which are expensive. Remote Sensing has the major advantage of comprehensive coverage and the four examples illustrate the potential of extrapolation from semi-automated habitat classifications. The potential for using these methods at national scales is likely to be limited by the need for validation of the automated images and the subsequent calculation of error terms. Existing major national monitoring programs are described, which still use mainly traditional in situ methods. The selection of relatively small numbers of representative samples from environmental classifications to obtain regional estimates reduces the need for large numbers of in situ survey sites and is therefore discussed. The recent development of the use of drones to acquire detailed imagery to support in situ habitat surveys is also covered. Finally, practical problems linked to the methods described in the paper are considered, as in some cases these will override the theoretical benefits of a particular approach. It is concluded that automated methods can enhance existing monitoring systems and should be considered in any biodiversity monitoring system as they represent an opportunity for reducing costs, if integrated with an in situ program.
\end{abstract}

Keywords: Remote Sensing, in situ data, Very High Resolution satellite imagery, LIDAR, drones, stratified random samples, extrapolation.

\section{INTRODUCTION}

Habitats are important as a measure of biodiversity at the landscape level (Bunce et al., 2013) and are used as the basis for strategic nature conservation planning in the European Union through European Biodiversity Strategy (European Commission, 2011). The 
Jongman R.H.G. et al. :A review of approaches for automated habitat mapping and their potential added value for biodiversity monitoring projects

Interpretation Manual (European Commission, 2013) of the Habitats of the European Union as defined in the Habitats Directive (92/43/EEC) includes a range of information mainly on plant species linked to the particular habitat, but also to some fauna, thus indicating the significance of habitats and how they are used for nature conservation objectives.

Habitat maps can be the basis for sampling vegetation efficiently at a $1 \mathrm{~km}$ square level, as described by Jongman et al. (2006), and are also used to report changes in vegetation and plant species e.g. in the Great Britain Countryside Survey (GB-CS, Norton et al., 2012). Such maps based on both field observations and remotely sensed information, are valuable in identifying the patterns and trends of biodiversity in larger areas and are essential for determining practical management options in nature reserves and other designated areas (Nagendra et al., 2013). Such maps are therefore necessary for obtaining estimates of extent and change in a variety of parameters related to biodiversity. In recent years new options have been developed for semi-automated mapping of habitats and their integration with existing in-situ field surveys, hence the examples included in the present paper.

The need for estimates of habitat extent at regional and national levels is widely recognized (e.g. Scholes et al., 2012). Coordination and harmonization of observation data collection for biodiversity both in situ and remotely sensed will increase its value by allowing more information to be extracted. The task ahead is to develop, at the lowest possible cost, reliable statistics on stock and change and produce well documented maps from field samples to populate the biodiversity indicators, for example, those requested in the Aichi Biodiversity Target 19 of the Convention on Biological Diversity (GEO BON, 2011) and the European Biodiversity Strategy (European Commission, 2011).

Currently all the major national monitoring programs in Europe use habitats but do not use automated mapping. In this paper we consider how this procedure could be incorporated in existing procedures or alternatively in any new monitoring initiative. Therefore we first discuss the principles of the methodology involved in habitat monitoring programs in Europe and then provide four examples of enlarging the area of in situ habitat maps using satellite imagery. Finally, the application of drones to reduce the time needed for mapping in the field is covered.

\section{IN SITU APPROACHES}

Terrestrial habitat mapping is done in many countries in Europe using various approaches and it is mostly based on phytosociology. In the Czech Republic the biotope mapping programme is carried out to support the establishment of the Natura 2000 network. Habitat mapping was based on the classifications described in the Biotopes Catalogue of the Czech Republic (Chytrý et al., 2001). Long-term vegetation mapping is the approach in Italy (http://www.vegitaly.it) carried out by the Italian Society for Vegetation Science (EEA, 2014). The main objectives of the Hungarian habitat mapping programme known as Database and Map of Hungarian Habitats (MÉTA, 2002-2005) were to map the natural vegetation of Hungary and build a habitat database (Molnár et al., 2007). In the Netherlands, systematic nationwide biodiversity monitoring programs are carried out, but these are focussing on species and vegetation (http://www.netwerkecologischemonitoring.nl/). This program makes use of permanent vegetation quadrats, carried out by volunteer networks on several species groups and is coordinated by the Central Statistics Office (CBS). Vegetation mapping is used in the Netherlands for monitoring Natura 2000 sites. In 2008 there were about 650 volunteer monitoring projects registered in the database of the FP7 project EUMON (http://eumon.ckff.si/index1.php). About $70 \%$ were species monitoring projects 
and have been carried out during one to several years. In Europe the major ongoing long-term national habitat monitoring programs are:

1. The Countryside Survey of Great Britain, (GB-CS) (www.countrysidesurvey.org.uk). This project started in 1978 and has had repeats in 1984, 1990, 1998 and 2007. Currently a further exercise has been started. An Environmental Classification of GB has been used to select representative stratified random dispersed $1 \mathrm{~km}$ squares. A wide range of ecological parameters have been included, for example habitats, vegetation, plant species and freshwater invertebrates. Estimates of stock and change have been produced with associated standard errors.

2. The Northern Ireland Countryside Survey (NICS, www.doeni.gov.uk/niea/biodiversity/nhresearch/nicountrysidesurvey-2.htm) covers over 200 squares of $0.25 \mathrm{~km}$ square in the province, stratified according to an environmental stratification (Cooper \& McCann, 2000). Estimates of stock and change have been produced and have been subsequently linked to GB CS to obtain UK figures, because the methods were compatible (Haines Young et al., 2000).

3. The National Inventory of Landscapes in Sweden (NILS, http://www.slu.se/en/collaborative-centres-and-projects/nils/). Representative sites of $5 \times 5 \mathrm{~km}$ square $\mathrm{km}$ were selected from the whole of Sweden in which the central $1 \mathrm{~km}$ square was used for field inventory. The inventory is a rolling sampling system with a return rate of 5 years of in total 631 squares. The $5 \times 5 \mathrm{~km}$ squares were interpreted using Infra-red photographs to provide stock and change estimates of habitats. Records were also made of vegetation and landscape features (Esseen et al., 2007).

4. The SISPARES project in Spain covers broad habitats (http://www.sispares.com/eng/). 206 representative $4 \times 4 \mathrm{~km}$ square units were selected from an Environmental Classification of Spain and aerial photographs were obtained for five dates. An analysis of landscape composition and configuration was made based on photographs taken at these dates between 1956 and 2003 (Ortega et al., 2008) and most recently in 2018.

5. Biodiversity Monitoring Switzerland (BDM, http://www.biodiversitymonitoring.ch/en/home.html) surveys the long term development of species diversity in selected plant and animal species linked to habitats. BDM focuses on trends and developments in the normal landscape of Switzerland, inspired by Swiss Range statistics and the Swiss National Forest inventory. BDM chose a systematic sampling grid consisting of three distinct nationwide networks (BDM coordination office, 2014).

Also outside Europe most monitoring programmes have a species, vegetation or process oriented approach such as the National Ecological Observatory Network (NEON) in the USA (Pennisi, 2010). The objective is to support understanding of ecological change and enables forecasting of future ecological conditions. NEON collects and processes data from fixed field sites located in 20 eco-regions across the continental US, Puerto Rico and Hawaii over a 30-year timeframe (https://www.neonscience.org/about/about/science-design). The Global Observation Research Initiative for Alpine Environments (GLORIA, https://gloria.ac.at/) observes species change in fixed high altitude sites globally (mountain tops) in a standardised way. The Circumpolar Biodiversity Monitoring Programme (CBMP, https://www.caff.is/about-the-cbmp) is a cooperative programme of all arctic countries monitoring key elements of ecosystems - including species, habitats, ecosystem structure, 
Jongman R.H.G. et al. :A review of approaches for automated habitat mapping and their potential added value for biodiversity monitoring projects

processes, functions and stressors to track biodiversity trends. Globally biodiversity monitoring is now being coordinated in the GEO BON community and a process of harmonisation is ongoing (https://geobon.org/). Improved methods for automated habitat mapping have also been included in the GEO BON objectives.

\section{Remote Sensing approaches}

One of the important aspects in biodiversity monitoring is that the costs of field surveys are high and a procedure is urgently needed to extend the limited sets of in situ data; hence the interest in semi-automated mapping using Remote Sensing (RS). Some biodiversity monitoring programmes have successfully used RS data, for well-defined habitats such as forests, e.g. Fraser et al. (2009) and handbooks have been developed such as the sourcebook for Monitoring Essential Biodiversity variables (EBVs) in Tropical Forests using RS (GOFC-GOLD, 2017) and the GEO handbook on Biodiversity observations (Walters \& Scholes, 2016). RS-enabled EBV's can support the global monitoring of biodiversity to a large extent, since in situ measurements are inevitably limited at this global scale (Skidmore et al., 2015; Pettorelli et al., 2016; Navarro et al., 2017).

Many large-scale land cover maps derived from satellite imagery such as the CORINE Land Cover map (EEA 2000, https://land.copernicus.eu/pan-european/corine-land-cover) have insufficient detail to identify habitats and therefore lack the capacity to record stock and changes in biodiversity. The CORINE Land Cover (CLC) inventory was initiated in 1985 and updated in 2000, 2006, 2012 and 2018. It consists of an inventory of land cover in 44 classes. CLC uses a Minimum Mapping Unit (MMU) of 25 hectares (ha) for areal phenomena and a minimum width of $100 \mathrm{~m}$ for linear phenomena. Levin (2006) emphasized that the minimum mappable unit of 25 hectares is not adequate for recording most biodiversity patches. Most other examples of RS mapping also do not have the necessary detail for biodiversity objectives but are produced to answer specific objectives related to the distribution patterns and extent of a particular resource e.g. forest cover. Monitoring also requires an understanding of the errors involved at each stage in the process, because otherwise real change cannot be separated from background noise. Furthermore, monitoring exercises have to use well described identical methods over the time scale of the measurements because otherwise observed changes may result from differences in recording method.

At present there are progressively more detailed images available that can support habitat mapping and monitoring such as the Copernicus high resolution layers (https://land.copernicus.eu/pan-european/high-resolution-layers/view) at $20 \mathrm{~m}$ resolution across Europe, and the Global Forest Change project (Hansen et al., 2013, http://earthenginepartners.appspot.com/science-2013-global-forest), based on consistently processed Landsat Imagery at $30 \mathrm{~m}$ scale. The resolution of the Sentinel 2 satellite scenes are depending on the spectral bands $10 \mathrm{~m}, 20 \mathrm{~m}$ or $60 \mathrm{~m}$, which is adequate for many habitats and linear features. This satellite also has so many regular passes that it enables cloud-free images to be obtained even from mountain areas with much cloud.

\section{Linking in situ and Remote Sensing approaches}

In the recent past several trials have been carried out to improve in situ data collection through linking it with RS observations. Four examples and their approaches are shortly described here with their common issues and differences. The examples are from the following locations:

1. The lowlands of Central Estonia. The site has limited relief and the land cover consists mainly of crops and forest but also some urban land (Lang et al., 2015). 
2. Wekeromse Zand in the Province of Gelderland, the Netherlands. This site is in a gently undulating sandy region. The land cover varies from sand dunes, heathland and coniferous forest and is surrounded by cultivated and urban land (Mücher et al., 2015).

3. Meijendel-Berkheide, in the Netherlands: changes in the structure of grey dunes within a dune complex (Mücher et al., 2017).

4. Mapping vegetation structure in the dunes and salt marshes of the Wadden Sea island of Ameland, the Netherlands, which is an almost flat area (Mücher et al., 2019).

In examples 1 and 2 use has been made of the standardised system of General Habitat Categories (GHCs) for consistent habitat recording in the field described by Bunce et al. (2008). GHCs can easily be translated into RS categories of the FAO land cover classification system (Di Gregorio \& Jansen, 2005) and vice versa (Tomaselli et al., 2013; Kosmidou et al., 2014). Semi-automated classification of high resolution RS imagery linked to GHCs are given in the four published examples which use different methods of mapping in order to demonstrate the potential of the approach. Examples 1, 3 and 4 are pixel based and example 2 is derived from a rule based system.

In all four examples LIDAR has been used for vegetation height calculation. These have been combined with different satellite data such as LANDSAT in the Estonian case study, while Worldview2 data has been used in the Wekeromse Zand study. A combination of Worldview2, Pleiades1B, GeoEye1 data and LiDAR data from 2008 and the Dutch altitude database from 2014 (https://www.pdok.nl/datasets) were used in the Meijendel-Berkheide project to monitor changes in vegetation height and cover at a one meter resolution and combined with an existing vegetation map to develop a protocol for identifying changes in grey dunes vegetation structure between the two years. In the example from the Wadden Sea island of Ameland, LIDAR and aerial photographs were used in both Rule-Based (RB) and Random-Forest (RF) methods to classify vegetation within a range of typical coastal conditions with some degree of variability. In the Estonia example GHCs were mapped in eight one kilometre squares in July 2010, as described in Lang et al. (2015). Each central km square was later extrapolated into eight surrounding squares. Analyses were carried out to ensure that sufficient data pixels were available to represent a given GHC. A total of 120 training areas were identified within the eight sites. Accuracy assessment was carried out by using all the training areas as validation. The areas of the habitats in all the squares were then extracted to obtain estimates of habitat extent. The nine squares are auto-correlated and the statistical implications need further study, although a similar layout was used by Elston et al. (1999). The example in Wekeromse Zand has made use of the Earth Observation Data for HAbitat Monitoring (EODHAM) system, which provided a standardized framework for consistent land cover and habitat mapping and monitoring of biodiversity in protected areas (Lucas et al., 2015). The image classification module of the EODHAM system uses Geographic Object-Based Image Analysis (GEOBIA) that enables the partition of RS imagery into meaningful image-objects in order to generate maps in a GIS-ready format.

The results from the semi-automated habitat mapping analyses of the Estonian site are given in Figure 1 and Table 1. The diagonal band across the image is a fault in the satellite image. The main GHCs are crops (CRO), deciduous forests (FPH/DEC) and mixed grasslands (CHE/LHE). The small urban parcels were not mapped as there was no training site in the central square and it was concluded that in any future exercise additional control points would have to be set up in the surrounding squares in order to get complete coverage. The figures from the extrapolation for these habitats are given for all the squares (Table 1). 


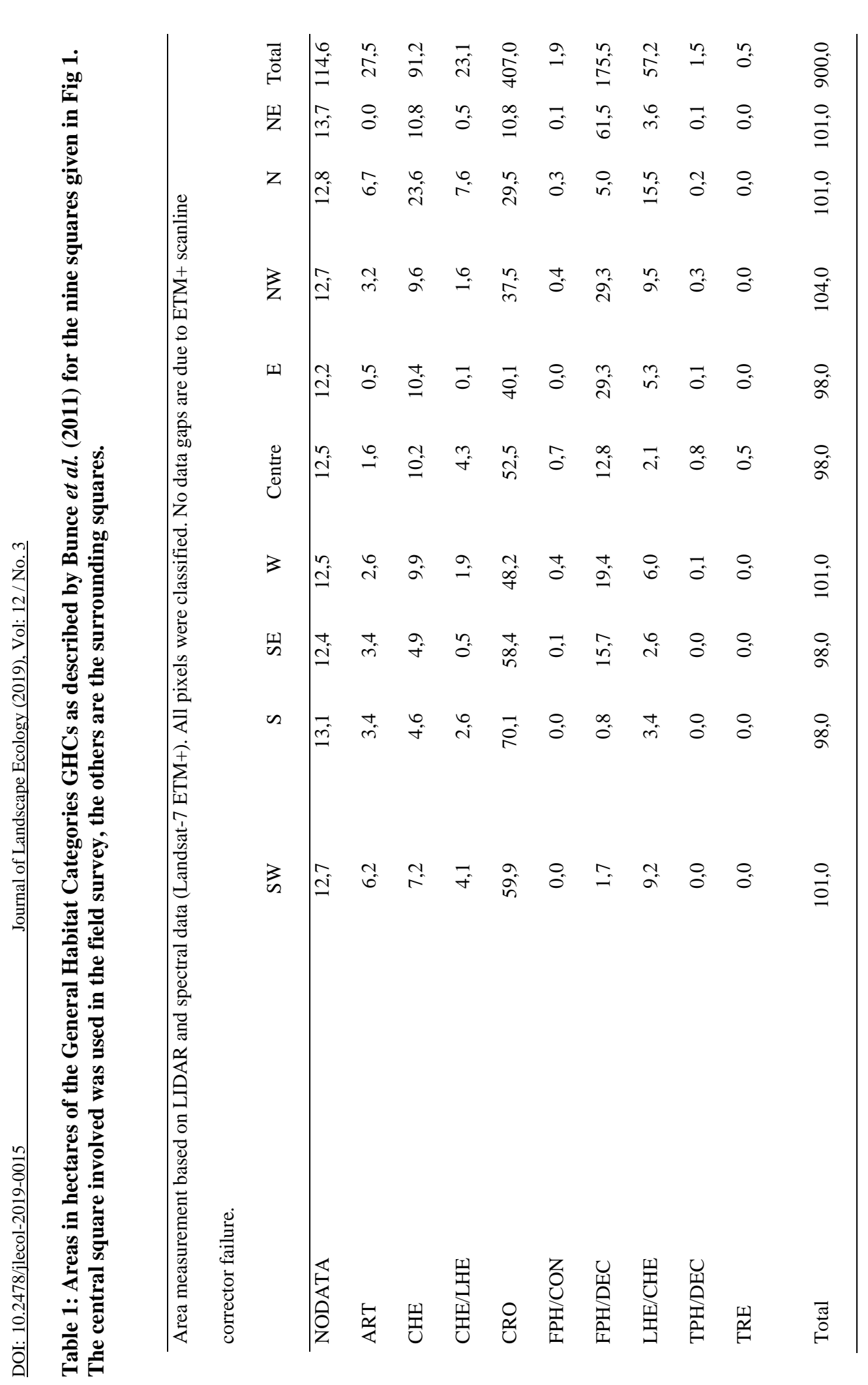


Fig. 1: Map of General Habitat Categories (GHCs), as defined by Bunce et al. (2011), in nine adjacent squares in central Estonia.

The eight squares surrounding the central square were extrapolated from the central square in which in situ data were recorded in 2010. The extrapolation was based on integration between Landsat TM and LIDAR. The principal habitats are crops (CRO), deciduous forest (FPH/DEC) and mixed grassland (CHE/LHE). The patches without data are either because there were no GHCs of that class in the central square or to absence of data on the satellite image, as described in the text.

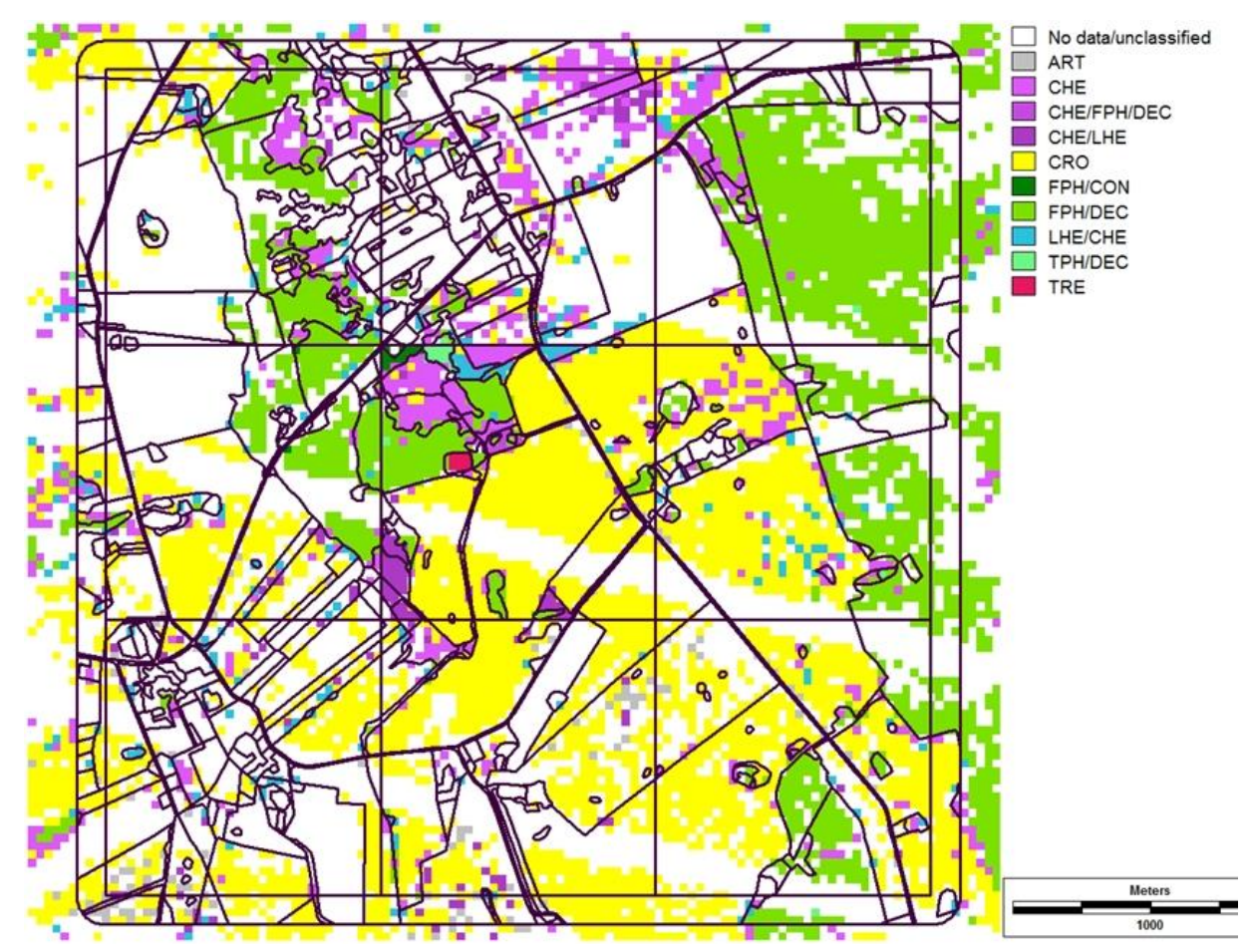

Figure 2 shows the results for the Dutch inland sand dunes. The conversion from LCCS to GHCs reflects known patterns and there were few interpretation problems. The area of bare sand (SAN) stands out and is linked to an area with lichens (CRY/LIC) and various types of heath habitats (SCH/EVR and mixtures). The land around the central area consists of various types of conifer and mixed forest (mainly FPH/CON and FPH/DEC/CON) although evergreen broadleaved forest (FPH/EVR) needed to be excluded as it does not occur in The Netherlands. The reason was a flaw in the rule base of EODHAM and shows that some correction of the results is required to remove such errors. 
Jongman R.H.G. et al. :A review of approaches for automated habitat mapping and their potential added value for biodiversity monitoring projects

Fig. 2: Map of General Habitat Categories (GHCs), as defined by Bunce et al. (2011) derived from LCCS classes in the site from the central eastern part of the Netherlands. The main categories are sand (SAN), heath (SCH/EVR), coniferous forest (FPH/SUM/CON which should be FPH/CON), crops (CRO) and urban (ART or NON).

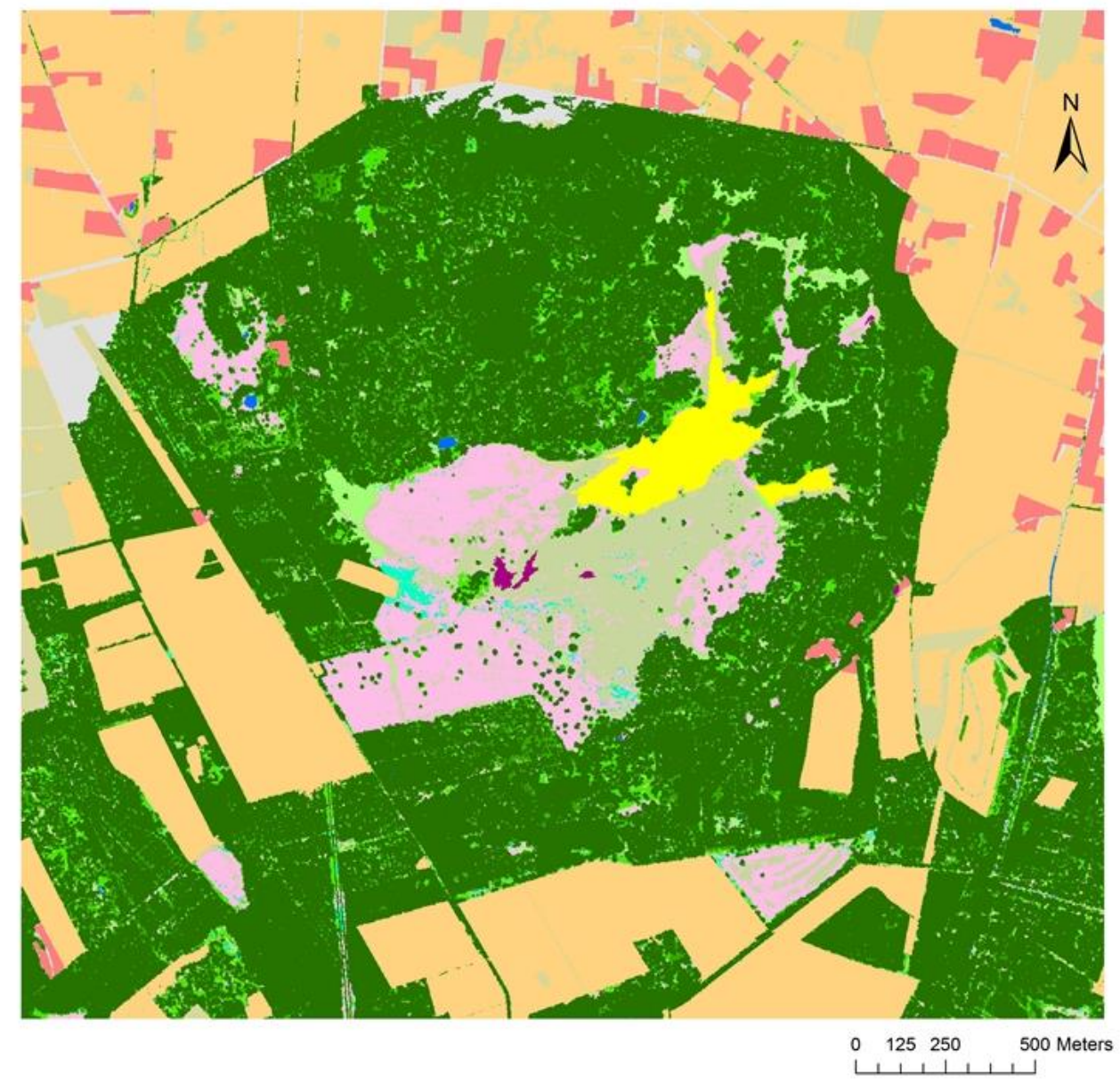

EODHAM Wekeromsezand
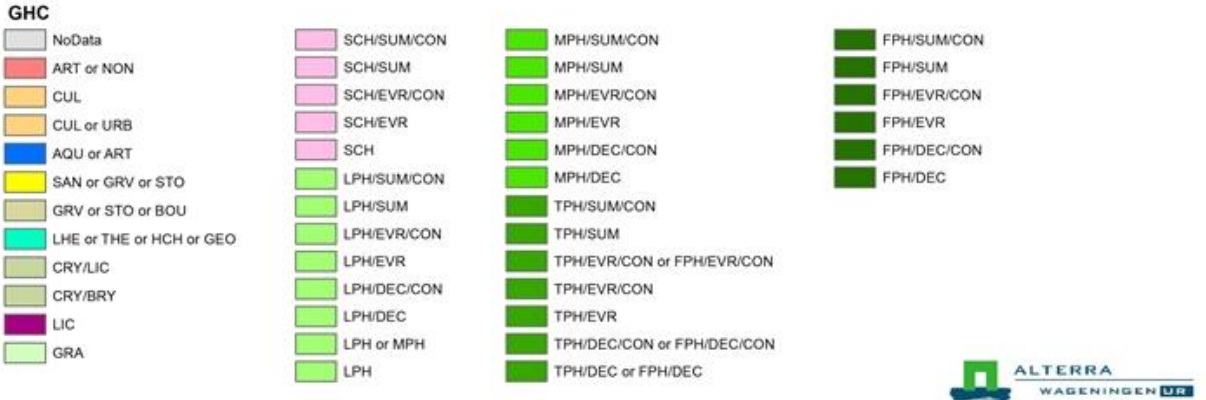
Figure 3 shows the results from Meijendel-Berkheide. This example shows how semi-automated RS linked with existing habitat maps can be used to follow changes in vegetation height and cover in a dune system between 2008 and 2014. The images show that sufficient detail was available for the managers of the site to be able to assess the ecological significance of the changes taking place. Whether such a detailed analysis would be feasible in the development of a monitoring system remains to be tested, but the technical potential is demonstrated.

Fig. 3: Monitoring change in the vegetation structure of grey dunes $(\mathbf{H} 2130)$ of the coastal Natura 2000 site, Meijendel-Berkheide, in the Netherlands, with readily accessible.

Very High Resolution (VHS) satellite imagery and LIDAR data. The methodology exploited LIDAR-data from AHN2 (2008) and AHN3 (2014) with almost simultaneous VHS imagery in order to detect changes in vegetation height and cover at a 1 meter spatial resolution. An existing habitat map was used to develop a protocol to find grey dunes (H2130) that showed significant changes in vegetation structure between 2008 and 2014.

VHR satellite imagery
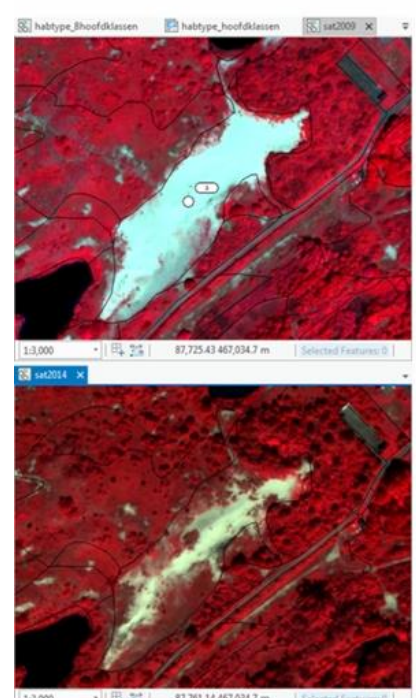

Vegetation cover
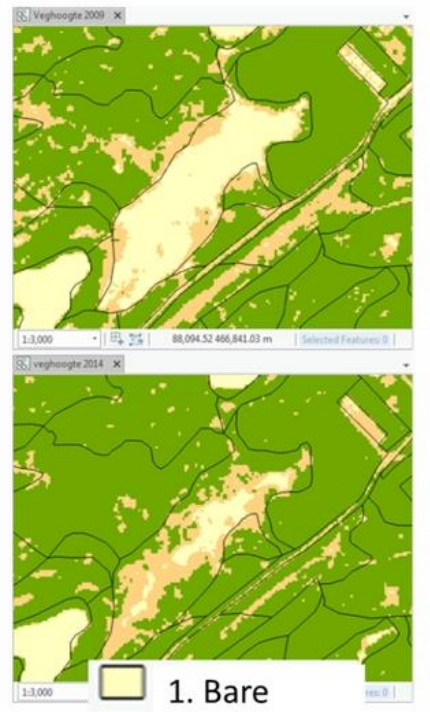

2. Covered

3. Vegetated
Vegetation height
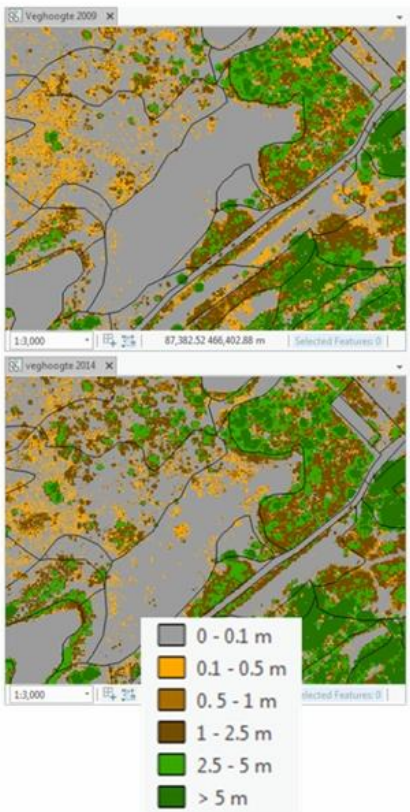

Figure 4 shows the results from the island of Ameland in the Wadden Sea based on a Random Forest (RF) classification. Both a rule based and a random forest classification have been applied with an overall accuracy of 84.1 and $86.4 \%$ respectively. Overall RF was preferred over RB as it was better able to handle the rules needed to distinguish more classes. High resolution satellite imagery is a good alternative to aerial photographs if these are not available. The results are a clear demonstration of how semi-automated systems can produce readily interpretable results, but there still remains a problem with their integration into a practical strategic monitoring system. 
Jongman R.H.G. et al. :A review of approaches for automated habitat mapping and their potential added value for biodiversity monitoring projects

Fig. 4: Vegetation structure map of the dunes of the Wadden island of Ameland resulting from random forest (RF) classification implemented based on nine feature classes as derived from aerial photo-graphs and LIDAR data from 2008 (Mücher et al, 2019). The overall accuracy is $86.4 \%$.

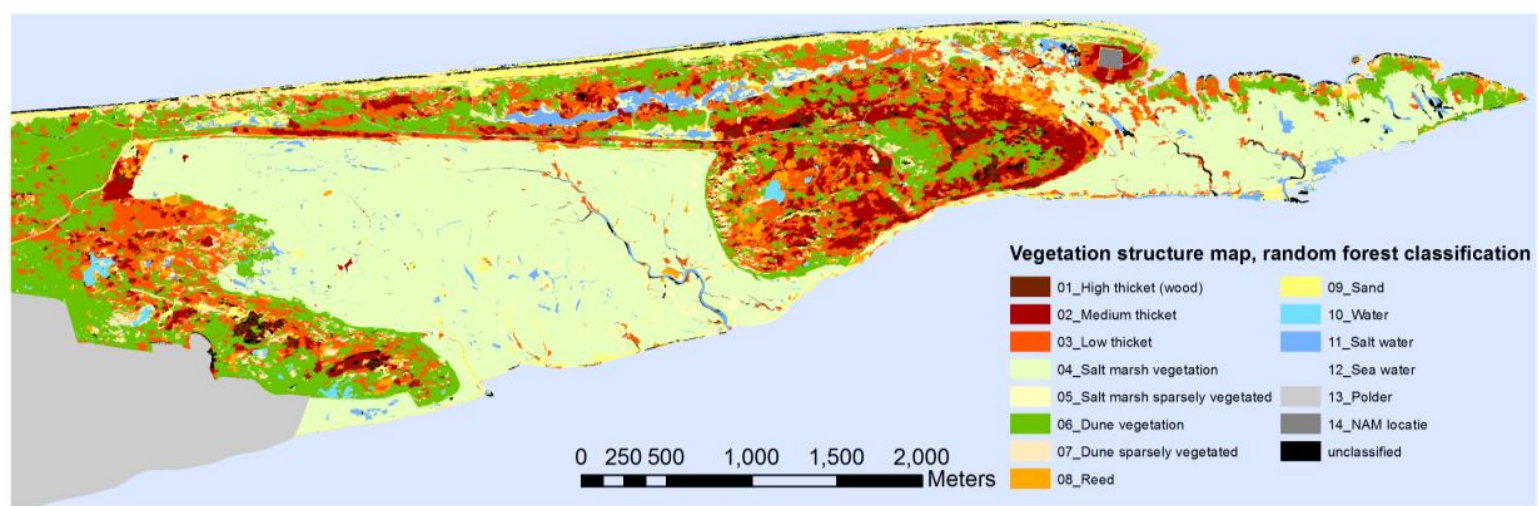

\section{DISCUSSION}

Setting up Biodiversity Observation Networks or monitoring programmes and maintaining them, requires preparation and well based institutional backing. The recent Swiss monitoring programme and the arctic CBMP show that it is possible and the results from the British Countryside Survey show the value of it for policy and management. The Estonian Agricultural Ministry is considering a new program to monitor changes in agricultural landscapes. The IPBES results and its global reports on biodiversity decline indicate that it is important to improve monitoring, to improve its efficiency and lower its costs. Long term financial backing of monitoring programmes is important. However, besides strategic aspects of setting up monitoring programmes for national and global assessments, there are also practical aspects and issues to be solved.

\section{The potential of automated habitat mapping}

The examples given in the present paper demonstrate the feasibility of automated habitat mapping. There are however practical problems of their application to strategic monitoring which may be summarised as follows:

- The practicality of extracting relatively large numbers of dispersed $1 \mathrm{~km}$ squares, or groups of squares, to cover the variation within a country or region.

- Consideration of time and expense required to process each individual sample is important, although the costs have fallen with the recent availability of Sentinel satellite data.

- Any new results using an RS system need to fit in with existing outputs of an existing monitoring scheme.

- For any new strategic monitoring system that is going to be set up it is important to test whether recently developed methods can be used to improve the identification of changes in habitats. However, in cases of fine grained habitat structure it is still 
better to exploit aerial photographs combined with LiDAR such as in the example of Ameland

- The problem of validation of RS images has often been raised, as there is frequently a lack of error terms for the estimates of areas.

Errors linked to in situ data are well understood, even although Hearn (2011) has shown that the most widely used method of vegetation mapping, i.e. phytosociology, is not sufficiently reliable for monitoring. While RS classifications are often being validated, most vegetation surveys are not. They lack accuracy assessment as well. This means that changes from subsequent vegetation or habitat maps are not reliable. The Countryside Survey of Great Britain uses both quality control and assurance and produces error terms on all the estimates of habitats. Based on these experiences the major sources of observer error may be summarised as follows (Anonymous, 2007):

1. The inherent variability of habitats at the landscape scale.

2. Differences in the ability of observers to identify species, which are reduced by having only high quality surveyors and by quality control.

There are also other critical sources of sampling errors not due to the observer: moment of observation as time of year has been shown to be a critical source of error and exact location, especially in natural areas. These errors can be reduced by carrying out all repeat surveys as closely as possible to the original date and the relocation of the exact boundaries can be assisted by modern GPS and careful digitising.

The use of environmental stratifications for stratified sampling and reducing sample size

A procedure which has been developed to reduce the sample number to obtain reliable estimates of habitat extent is the application of environmental stratifications to select representative $1 \mathrm{~km}$ squares for field survey - or automated samples. In 2007 in GB $5911 \mathrm{~km}$ squares had been selected from the 32 classes of the environmental classification covering $118,000 \mathrm{~km}$ squares in the country to obtain estimates of the stock and change of habitats, as well as vegetation and species composition (Norton et al., 2012). A similar European and a global stratification have been completed by Metzger et al. (2005, 2013). They have described how it could be used to select a comparable series of sites for Europe. They provide an overview of this methodology, which involves the statistical analysis of climatic and environmental data to classify $1 \mathrm{~km}$ squares into strata which can then be sampled to obtain estimates of habitat extent and composition for any given domain (Jongman et al., 2006). Geijzendorffer \& Roche (2013) have shown that the GHCs are sufficiently robust to record habitats consistently. More recently Villoslada et al. (2017) have carried out a similar procedure at a smaller scale in the 45,000 $1 \mathrm{~km}$ squares in Estonia.

\section{LIDAR DATA}

This paper has shown that habitat classifications and changes in their vegetation structure derived from RS, preferably combining optical and LIDAR data, can support the field surveillance and monitoring of biodiversity. The examples in this paper are all in temperate regions of Europe, but trials of similar procedures also have been carried out in the dry region in Almeria, Southern Spain. The area surveyed had sparse vegetation with much bare ground and rock. The available satellite imagery was from a different season than field survey and matched poorly with the in situ data emphasizing that the timing of the acquisition of imagery should match the date of the survey. Tests of the LIDAR point cloud data by Mücher et al. (2015) have shown that it can provide reliable information about vegetation height and 
Jongman R.H.G. et al. :A review of approaches for automated habitat mapping and their potential added value for biodiversity monitoring projects

density and can be used to assist the definition of habitats and to extend the in situ data from the centre square to the surrounding squares.

A further option would be to identify separate training points within parcels of a given GHC that may have an observable different reflectance. For example a habitat mapped as artificial could consist of white dirt roads, black tarmac roads, grey roofs or greenhouses or a habitat mapped as crops could be pale green (barley) or dark green (oil seed rape). Training sites could then be placed in these areas and the procedure followed as in the first example in Estonia. The unknown areas in the final map, of Figure 1 would then be completed. Tests are needed of this procedure, as it has much potential.

The characteristics and availability of LIDAR data vary widely across Europe and the data quality of a given site need to be assessed before use. Flying altitude, pulse energy and pulse repetition have a major influence on the final accuracy, but this also is valid for the GPS data, which are used to calculate the trajectory. Nevertheless using LIDAR data in vegetation height categories will help to determine habitats in scrub and forest categories, especially in the Mediterranean region. LIDAR data need to be linked, if possible, to in situ data. The availability of simultaneous satellite imagery is also important but in many cases cannot be determined before field work. Overall accuracy and error estimation at each site are an essential part of the process and has a major influence in the degree of change that can be detected.

Monitoring of habitats using RS is difficult where it concerns individual plant species, but can be used when it concerns changes in vegetation structure. In the Netherlands, for Meijendel-Berkheide open LIDAR-data have been used to derive terrain models, in combination with freely available Very High Resolution satellite data through the national satellite data portal https://www.spaceoffice.nl/nl/satellietdataportaal/) and for Ameland LIDAR in combination with commonly shared aerial photographs (https://www.pdok.nl/), have been exploited to develop methodologies that can help to increase the updating frequency of vegetation structure maps, based on respectively vegetation height and cover, as described in the results section. This approach requires specific decision rules in relation to vegetation height and/or cover, which have to be agreed by land managers and the nature conservation community (Jongman, 2013).

\section{The use of drones as a way forward?}

In Northern Europe, monitoring using satellite imagery can be problematic due to cloud cover. In 2012, field data were collected in Central Estonia for coordination with imagery but no RS data were available for that period of year so the project failed. Drones may then be of help. In recent years there have been rapid developments in the technology of drones and a wide range of types are now available varying from fixed wing machines to multirotor platforms. The use of drones is a separate and therefore rapidly expanding technology. For example, drone imagery has been used in an inland dune area in the Netherlands with various stages of scrub encroachment and has been used directly for field surveys and subsequent vegetation mapping to determine its species composition. Drones can therefore determine levels of detail at a resolution of centimetres that cannot be seen from satellites. Drones can also be used to obtain LIDAR, thermal, hyperspectral or multispectral imagery, which can yield much information on biodiversity if interpreted by experts such as Ståhl et al. (2011) have shown in the NILS project. If coordinated with in situ visits, there would be sufficient detail to map habitats accurately, especially if simultaneous observations were made by surveyors. Drone images can also be used to assist mapping patches with difficult access such as cliffs and wetlands. However at least in GB it appeared that problems can be raised with gaining permission to fly drones in many of the sample $1 \mathrm{~km}$ squares. 
Planning monitoring programmes and combining field surveys with drone imagery is dependent on weather conditions. Modern satellites have more regular passes so this is no longer a major problem but in the difficult weather and terrain of the mountains in the North-West of Great Britain it can still be a problem. Planning a major programme of field work linked to drones also has risks because the weather might not be appropriate to cover all the target areas, for example strong wind hampers flying and may reduce the area that can be covered because of heavier battery use. In general battery power restricts the flying distance of drones and batteries with a high power capacity are heavy. Rain and freezing temperatures are also a problem for flying drones. Also if there is low cloud the camera does not produce good images. Some areas have restricted access, such as military land, the surroundings of airfields, border corridors, and some nature protection areas that are totally closed for drone usage or temporally closed during the nesting season.

\section{CONCLUSIONS}

The present paper has demonstrated the potential and the restrictions of automated habitat mapping using satellite imagery and LIDAR data provided by satellites and drones. Recent developments in machine learning also have potential but it remains a problem to integrate these into a coherent new monitoring programme for habitats, either at the EU or national levels. However, such an approach is urgently required because of the current lack of reliable figures and the lower costs linked to automation present a major opportunity that needs to be taken. The use of drones in obtaining local data, especially where satellite and in situ observation is problematic might have an added value in monitoring programmes.

\section{ACKNOWLEDGEMENTS}

Initial studies using this procedure were carried out in the EBONE project (www.wageningenur.nl/EBONE, FP7, Grant agreement 212322) which ran from 2008 to 2012 and two of the studies described in the present paper formed part of this project. The Biodiversity Multi-Source Monitoring System (BIOSOS) project (http://www.biosos.eu/project.htm FP7, Grant agreement 263435) that ran from 2010 until the end of 2013 has developed the procedures further.

\section{REFERENCES}

Anonymous (2007). Countryside Survey 2007, Field handbook, Vegetation plots.

BDM Coordination Office (2014). Swiss Biodiversity Monitoring BDM. Description of Methods and Indicators. Federal Office for the Environment, Bern. Environmental studies no. 1410.103 pp.

Bunce, R.G.H., Metzger, M.J., Jongman, R.H.G., Brandt, J., de Blust, G., Elena-Rossello, R., Groom, G.B., Halada, L., Hofer, G., Howard, D.C., Kovár̆, P., Mücher, C.A., Padoa-Schioppa, E., Paelinx, D., Palo, A., Perez-Soba, M., Ramos, I.L., Roche, P., Skånes, H. \& Wrbka, T. (2008). A standardized procedure for surveillance and monitoring European habitats and provision of spatial data. Landscape Ecology, 23, 11-25.

Bunce, R.G.H., Bogers, M.M.B., Roche, P., Walczak, M., Geijzendorffer, I.R. \& Jongman, R.H.G. (2011). Manual for Habitat and Vegetation Surveillance and Monitoring. Temperate, Mediterranean and Desert Biomes. Alterra Report 2154. Alterra, Wageningen. 
Jongman R.H.G. et al. :A review of approaches for automated habitat mapping and their potential added value for biodiversity monitoring projects

https://wur.on.worldcat.org/oclc/710028113.

Bunce, R.G.H, Bogers, M.M.B., Evans, D., Halada, L., Jongman, R.H.G., Mücher, C.A., Bauch, B., de Blust, G., Parr, T.W. \& Olsvig-Whittaker, L. (2013). The significance of habitats as indicators of biodiversity and their links to species. Ecological Indicators, 33, 19-25. DOI: 10.1016/j.ecolind.2012.07.014.

Chytrý, M., Kučera, T., \& Kočí, M., Eds., (2001) Habitat catalogue of the Czech Republic. A manual to European programmes Natura 2000 and Emerald, p. 304, Prague, Agentura ochrany př́rody a krajiny ČR (in Czech).

Cooper, A. \& McCann, T.P., (2000). The Northern Ireland Countryside Survey 2000: summary report on Broad Habitats. University of Ulster, Coleraine.

Di Gregorio, A. \& Jansen L.J.M. (2005). Land cover classification system (LCCS) classification concepts and manual for software. Version 2. Technical Report 8. FAO Environment Resources Services Series, Rome.

EEA (2000). CORINE land cover technical guide - addendum 2000. Report no. 40. Copenhagen: European Environment Agency.

EEA (2014). Terrestrial habitat mapping in Europe: an overview. EEA Technical report no 1/2014. Copenhagen: European Environmental Agency. ISSN 1725-2237

Elston, D.A., Gauld, J.H., Miller, J.A., Shewry, M.C. \& Underwood, F.M. (1999). The National Countryside Monitoring Scheme: accuracy assessment. Scottish Natural Heritage Research, Survey and Monitoring Report nr. 133.95 pp.

Esseen, P-A., Glimskär,A., Ståhl, G. \& Sundquist, S. (2007). Field instruction for the national inventory of the landscape in Sweden, NILS. Year 2007, SLU-SRH, 90183 Umeå

European Commission (2011). Communication from the commission to the European Parliament, the Council, the Economic and Social Committee and the Committee of the Regions. Our life insurance, our natural capital: an EU biodiversity strategy to 2020. Retrieved May 21, 2019, from http://ec.europa.eu/environment/nature/biodiversity/comm 2006/pdf/2020/1_EN_ACT_part1_v7\%5B1\%5D.pdf.

European Commission (2013). Interpretation manual of European Union habitats. EUR 28. European Commission DG Environment, Nature ENV B.3, 144 pp.

Fraser R.H., Olthof, I. \& Pauliot D. (2009). Monitoring land cover change and ecological integrity in Canada's national parks. Remote Sensing of Environment, 113, 1397-1409.

Geijzendorffer, G.R. \& Roche, P.K. (2013). Can monitoring schemes provide indicators for ecosystem services? Ecological Indicators, 33, 148-157.

GEO BON (2011). Adequacy of Biodiversity Observation Systems to support the CBD 2020 Targets. Retrieved November 4, 2014, from http://www.earthobservations.org/documents/ cop/bi_geobon/2011_cbd_adequacy_report.pdf.

GOFC-GOLD, (2017). A Sourcebook of Methods and Procedures for Monitoring Essential Biodiversity Variables in Tropical Forests with Remote Sensing. Retrieved September 15, 2017, from http://geobon.org/products/books/, Publisher: UNCBD COP-13, GOFC-GOLD Land Cover Project Office,

Haines-Young, R.H., Barr, C.J., Black, H.I.J., Briggs, D.J., Bunce, R.G.H., Clarke, R.T., Cooper, A., Dawson, F.H., Firbank, L.G., Fuller, R.M., Furse, M.T., Gillespie, M.K., Hill, R., Hornung, M., Howard, D.C., McCann, T., Morecroft, M.D., Petit, S., Sier, A.R.J., Smart, S.M., Smith, G.M., Stott, A.P., Stuart, R.C. \& Watkins, J.W. (2000). Accounting for nature: assessing habitats in the UK countryside. DETR, London. 
Hansen, M.C., Potapov P.V., Moore, R., Hancher, M., Turubanova, S.A., Tyukavina, A., Thau D., Stehman S.V., Goetz, S.J., Loveland, T.R., Kommareddy, A., Egorov, A., Chini, L., Justice, C.O., \& Townshend, J.R.G. (2013). High-resolution global maps of 21st-century forest cover change. Science, 342:850-853.

Hearn, S.M., Healey, J.R., McDonald, M.A., Turner, A.J., Wong, J.L.G. \&Stewart, G.B. (2011). The repeatability of vegetation classification and mapping. J. of Env. Management, 92(4), 1174-1184, Doi:10.1016/j.jenvman.2010.11.021.

Jongman, R.H.G., Bunce, R.G.H., Metzger, M.J., Mücher, C.A., Howard, D.C \& Mateus, V.L. (2006). A statistical Environmental Stratification of Europe: objectives and applications. Landscape Ecology: 21:409-419.

Jongman, R.H.G., (2013). Biodiversity observation from local to global. Ecological Indicators. DOI: http://dx.doi.org/10.1016/j.ecolind.2013.03.012.

Kosmidou, V., Petrou, Z., Bunce, R.G.H., Mücher, C.A., Jongman, R.H.G., Bogers, M.M.B., Lucas, R.M., Tomaselli, V., Blonda, P., Padoa-Schioppa, E., Manakos, I. \& Petrou, M. (2014). Harmonization of the Land Cover Classification System (LCCS) with the General Habitat Categories (GHC) classification system. Ecological Indicators, 36, 290-300.

Lang, M., Vain, A., Bunce, R.G.H., Jongman, R.H.G., Raet, J., Sepp, K., Kuusemets, V., Kikas, T., \& Liba, N., (2015). Extrapolation of in situ data from 1-km squares to adjacent squares using remote sensed imagery and airborne LIDAR data for the assessment of habitat diversity and extent. Environmental Monitoring and Assessment, 187 (3), 1-16. DOI: http://dx.doi.org/10.1007/s10661-015-4270-7.

Levin, G. (2006). Farm size and landscape composition in relation to landscape change in Denmark. GeografiskTidsskrift-Danish Journal of Geography, 106, 45-60.

Lucas, R., Blonda, P., Bunting, P., Jones, G., Inglada, J., Arias, M., Kosmidou, V., Petrou, Z.I., Manakos, I., Adamo, M., Charnock, R., Tarantino, C., Mücher, C.A., Jongman, R.H.G., Kramer, H., Arvor, D., Honrado, J.P., \& Mairota, P., (2015). The Earth Observation Data for Habitat Monitoring (EODHaM) system. J of Applied Earth Observation and Geoinformation 37: $17-28$

Metzger, M.J., Bunce, R.G.H., Jongman, R.H.G., Mücher, C.A. \& Watkins, J.W. (2005). A climatic stratification of the environment of Europe. Global Ecology and Biogeography, 14, 549-563.

Metzger, M.J., R.G.H. Bunce, R.H.G. Jongman, R. Sayre, A. Trabucco, R. Zomer (2013). A high resolution bioclimate map of the world: a unifying framework for global biodiversity research. Global Ecology and Biogeography, 22: 630-638. DOI: 10.1111/geb.12022

Molnár, Z., Bartha, S., Seregélyes, T., Illyés, E., Botta-Dukát, Z., Tímár, G., Horváth, F., Révész, A., Kun, A., Bölöni, J., Biró, M., Bodonczi, L., József, A.D., Fogarasi, P., Horváth, A., Isépy, I., Karas, L., Kecskés, F., Molnár, C., Ortmann-né Ajkai, A. \& Rév, S., (2007). A grid-based, satellite-image supported, multi-attributed vegetation mapping method (MÉTA), Folia Geobotanica, 42(3), 225-247.

Mücher, C.A., Roupioz, L., Kramer, H., Bogers, M.M.B., Jongman, R.H.G., Lucas, R.M., , Petrou, Z., Kosmidou, V.E., Manakos, I., Padoa-Schioppa, E., Adamo, M., \& Blonda, P., (2015). Synergy of Airborne LiDAR and Worldview-2 satellite imagery for land cover and habitat mapping: a BIO_SOS-EODHaM case study for the Netherlands. J. of Applied Earth Observation and Geoinformation 37: 48-55.

Mücher, C.A., Kramer, H., Van der Wijngaart, R., \& Huiskes, R. (2017). Ontwikkelen van een Remote Sensing monitoringssystematiek voor vegetatiestructuur; Pilotstudie: detectie 
Jongman R.H.G. et al. :A review of approaches for automated habitat mapping and their potential added value for biodiversity monitoring projects

verruiging Grijze Duinen (H2130) voor het Natura 2000-gebied Meijendel-Berkheide. Wageningen, Wageningen Environmental Research, Report 2838.

Mücher, C.A., Kramer, H., Najafabadi, M.R., Kooistra, L., Kuiters, A.T., \& Slim, P.A. (2019). Exploiting low-cost and commonly shared aerial photographs and LiDAR data for detailed vegetation structure mapping of the Wadden Sea island of Ameland. SDRP Journal of Earth Sciences \& Environmental Studies 4 (1): 502-515.

Nagendra, H., Lucas, R., Honrado. J.H., Jongman, R.H.G., Mairota, P., Tarantino, C., \& Adamo, M. (2013). Remote Sensing for Protected Area Assessment: Monitoring Habitat Area, Condition, Biodiversity and Threats. Ecological Indicators, 33:45-59. DOI: 10.1016/j.ecolind.2012.09.014.

Navarro, L. M.; Fernández N; Guerra, C.; Guralnick, R.; Kissling, W. D.; Londoño M. C.; Muller-Karger, F.; Turak, E.; Balvanera, P.; Costello, M. J, Delavaud, A., ElSerafy, G., Ferrier, S., Geijzendorffer, I., Geller, G.N., Jetz, W., Kim, E-S., Kim, H., Martin, C.S., McGeoch, M.A., Mwampamba, T.H., Nel, J.L., Nicholson, E., Pettorelli, N., Schaepman, M.E., Skidmore, A., Sousa Pinto, I., Vergara, S., Vihervaara, P., Xu, H., Yahara, T., Gill, M. \& Pereira, H.M. (2017). Monitoring Biodiversity Change through Effective Global Coordination. Current Opinion in Environmental Sustainability, 29, 158-169 DOI: 10.1016/j.cosust.2018.02.005.

Norton, L.R., Maskell, L.C., Smart, S.S., Dunbar, M.J., Emmett, B.A., Carey, P.D., Williams, P., Crowe, A., Chandler, K., Scott, W.A., \& Wood, C.M. (2012). Measuring stock and change in the GB countryside for policy - Key findings and developments from the Countryside Survey 2007 field survey. J. of Env Management 113 (30): 117-127.

Ortega, M., R.G.H. Bunce, J.M. García del Barrio \& R. Elena-Rosselló, (2008). The relative dependence of Spanish landscape pattern on environmental and geographical variables over time. Investigación Agraria: Sistemas y Recursos Forestales 2008 17(2), 114-129, ISSN: 1131-7965

Pennisi, E. (2010). A Groundbreaking Observatory Monitor the Environment. Science, New Series, Vol. 328, No. 5977: 418-420.

Pettorelli, N., Wegmann, M., Skidmore, A., Mücher, C.A., Dawson, T.P., Fernandez, M., Lucas, R., Schaepman, M.E., Wang, T., O’Connor, B., Jongman, R.H.G., Kempeneers, P., Sonnenschein, R., Leidner, A.K., Böhm, M., He, K.E., Nagendra, H., Dubois, G., Fatoyinbo, T., Hansen, M.C., Paganini, M., de Klerk, H.M., Asner, G., Kerr, J., Estes, E.B., Schmeller, D.S., Heiden, U., Rocchini, D., Pereira, H.M., Turak, E., Fernandez, N., Lausch, A., Cho, M.A., Alcaraz-Segura, D., McGeoch, M.A., Turner, W., Mueller, A., St-Louis, V., Penner, J. and Geller, G.N, (2016). Framing the concept of Satellite Remote Sensing Essential Biodiversity Variables: challenges and future directions. Retrieved March 25, 2016, from onlinelibrary.wiley.com/doi/10.1002/rse2.15/pdf. Remote Sensing in Ecology and Conservation (Open Access).

Scholes, R.J., Walters, M., Turak, E., Saarenmaa, H., Heip, C.H.R., O'Tuama, E., Faith, D.P., Mooney, H.A., Ferrier, S., Jongman, R.H.G, Harrison, I.J., Yahara, T., Pereira, H.M., Larigauderie, A. \& Geller, G. (2012) Building a global observing system for biodiversity. Current Opinion in Environmental Sustainability, 4,139-146.

Skidmore, A.K., Pettorelli, N., Coops, N.C., Geller, G.N., Hansen, M., Lucas, R., Mücher, C.A., O’Connor, B., Paganini, M., Pereira, H.M., Schaepman, M.E., Turner, W., Wang, T., \& Wegmann, M., (2015). Agree on biodiversity metrics to track from space. NATURE, 23 July 2015, Vol. 523, pp 403-405. 
Ståhl, G., Allard, A., Esseen, P.A., Glimskär, A., Ringvall, A., Svensson, J., Sundquist, S., Christensen, P., Torell, A.G., Högström, M., Lagerqvist, K., Marklund, L., Nilsson, B. \& Inghe, O. (2011). National Inventory of Landscapes in Sweden (NILS) - scope, design, and experiences from establishing a multiscale biodiversity monitoring system. Environmental Monitoring and Assessment, 173, 579-595.

Tomaselli, V., Dimopoulos, P., Marangi, C., Kallimanis, A.S., Adamo, M., Tarantino, C., Panitsa, M., Terzi, M., Veronico, G., Lovergine, F., Nagendra, H., Lucas, R., Mairota, P., Mücher, C.A. \& Blonda, P. (2013). Translating land cover/land use classifications to habitat taxonomies for landscape monitoring: a Mediterranean assessment. Landscape Ecology, 28, 905-930.

Villoslada, M., Bunce, R.G.H., Sepp, K., Jongman, R.H.G., Metzger, M.J., Kull, T., Raet, J., Kuusemets, V., Kull, A. \& Leito, A. (2017). A framework for habitat monitoring and climate change modelling: Construction and validation of the Environmental Stratification of Estonia. Regional Environmental Change, 17 (2): 335-349. DOI 10.1007/s10113-016-1002-7.

Walters, M. and R. Scholes (Eds), (2016). The GEO handbooks on biodiversity observation networks, Springer Open DOI: 10.1007/978-3-319-27288-7. 